\title{
Chapter
}

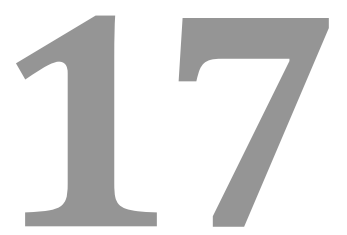

\section{EXPLORING TREATMENTS FOR OCULAR SURFACE DISEASES}

Pallavi Deshpande, Ilida Ortega, and Sheila MacNeil*

Kroto Research Institute, University of Sheffield, Broad Lane, Sheffield S3 7HQ, United Kingdom 


\section{Contents}

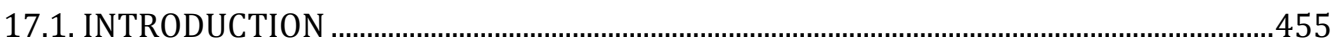

17.2. BACKGROUND..............................................................................................................455

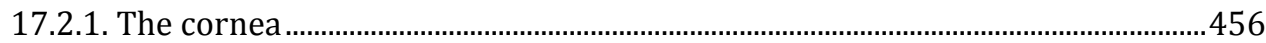

17.2.1.1. The corneal epithelium ...........................................................................457

17.2.2. Limbal stem cell deficiency …………………………........................................458

17.2.2.1. Partial limbal stem cell deficiency ..........................................................459

17.2.2.2. Total limbal stem deficiency ..................................................................459

17.2.3. Clinical treatments of limbal stem cell deficiency ................................................460

17.2.3.1. Conjunctival transplantation ..................................................................460

17.2.3.2. Keratoepithelioplasty .........................................................................460

17.2.3.3. Conjunctival limbal transplantation........................................................461

17.2.3.4. Living related conjunctival limbal allograft ..........................................461

17.2.3.5. Keratolimbal allograft................................................................................461

17.2.3.6. Ex vivo expansion of limbal epithelial cells.............................................461

17.3. USING DIFFERENT CELL TYPES AND CARRIERS FOR LIMBAL STEM CELL

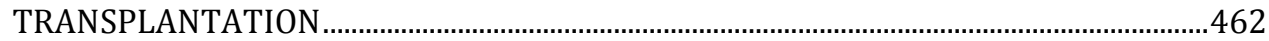

17.3.1. Transplantation of different cell types ..................................................................462

17.3.1.1. Limbal cell carriers ...................................................................................463

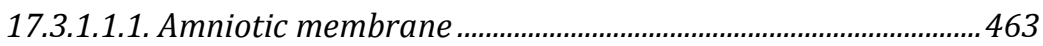

17.3.1.1.2. Other natural polymers as a carrier..............................................464

17.3.1.1.3. Synthetic polymers as a carrier..................................................465

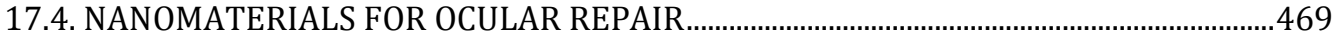

17.5. EXPANSION OF CELLS ON THE CARRIER.............................................................................471

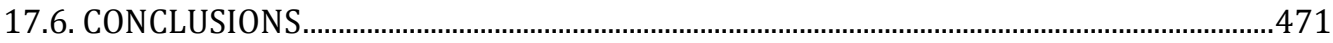

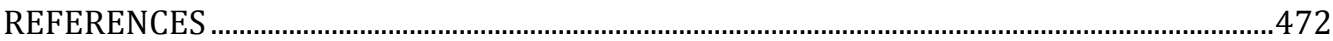




\subsection{INTRODUCTION}

Tissue engineering is a rapidly evolving field which can provide options to treat a wide range of diseases. Using tissue engineering, researchers have recently transplanted whole tissues such as the trachea [1] and the vagina [2] into patients and parts of damaged tissues, for example skin [3] (which has actually been in use since the early 1980s), urethra [4], cornea [5], and pancreatic islets [6].

Tissue engineering is based on growing cells on or within substrates commonly known as scaffolds. Scaffolds can be decellularised tissue (for example de-epidermised dermis [7] or decellularised pancreas [8]) or fabricated from either natural [9] or synthetic polymers [10] in the form of films [11], hydrogels [12] or electrospun scaffolds [13]. However, consideration must be given as to whether the technique developed is for laboratory based research purposes or for clinical translation. Using decellularised tissue for human transplantation requires tissues to be sourced with full ethical consent of the donors or relatives, which are handled through a tissue bank in order to minimise the risk of disease transmission [14]. This requires the establishment of well-run tissue banks which is a time consuming process and despite very best banking practices it is not possible to completely eliminate all risks of viral transmission. Accordingly, to avoid any risk of disease transmission using human tissue and delays in its use, ready-to-use synthetic alternatives for scaffolds may be better option.

A large amount of work has been carried out to investigate how to deliver cells to tissue surfaces, particularly for the cornea. This chapter describes the diseases that can affect the ocular surface, the current clinical treatments and the possible future treatments including the use of nanotechnology in the treatment of corneal diseases.

\subsection{BACKGROUND}

The eye consists of several different tissues, each playing a key role in vision (Figure 1). Damage to any of the tissues can adversely affect sight ranging from blurred vision to total blindness. 


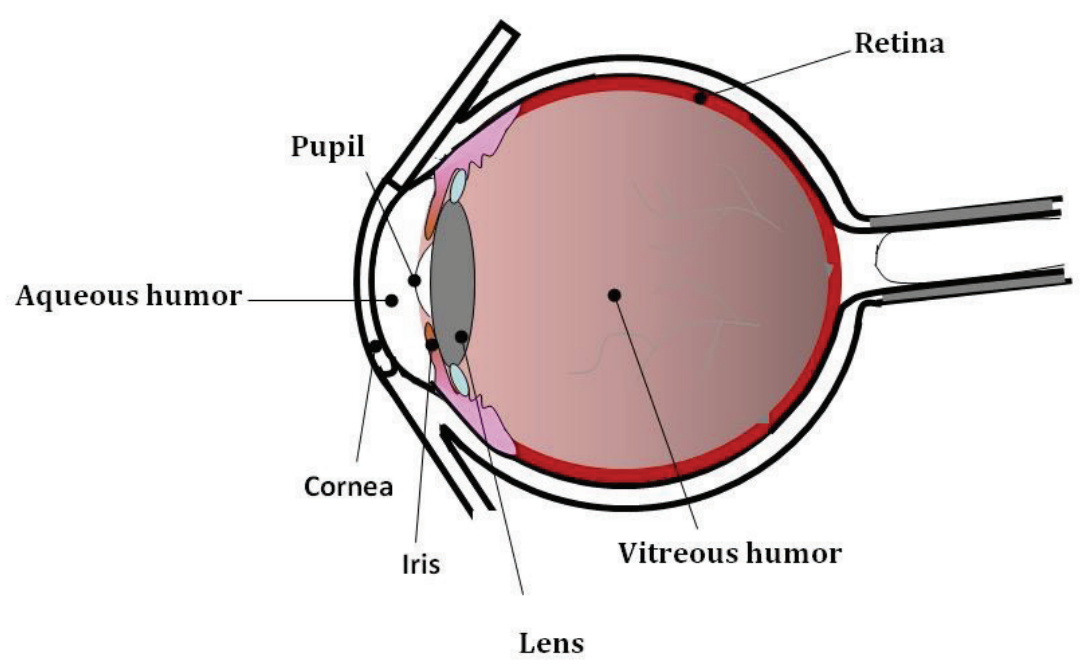

Figure 1. Schematic diagram of the cornea

The cornea is the first tissue that light passes through when entering the eye [15], after which it undergoes refraction several times as it moves through the different tissues of the eye until it eventually falls on to the retina.

\subsubsection{The cornea}

The cornea is an avascular [16], transparent tissue [17] with a major role to play in vision.

Similar to skin, maintenance of the barrier function of the cornea is vital, without which the tissue is prone to infection and disease, causing blurred vision and sometimes blindness. The central cornea does not contain any blood vessels or lymphatic vessels [18] however, the limbal area situated at the periphery of the cornea is highly vascularised [19] supplying nutrients to the residing adult stem cells and highly proliferative epithelial cells. A continuous supply of tear fluid to the front of the eye keeps the cornea from drying out. The tears play a crucial role in washing away debris which can lead to infection but at the same time provide nutrients to cells.

The cornea is $\sim 500 \mu \mathrm{m}$ thick [15] and consists of five different layers: the epithelium, Bowman's membrane, stroma, Descemet's membrane and endothelium (Figure 2). 


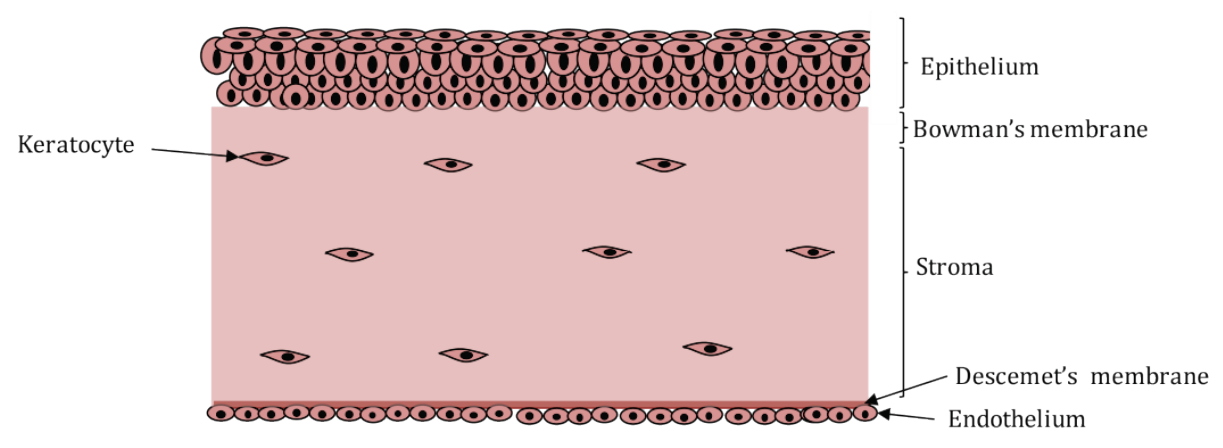

Figure 2. Schematic of the cross-section of the cornea

The corneal epithelium is the outermost layer of the cornea and is $\sim 50 \mu \mathrm{m}$ thick. Below the epithelium is the Bowman's membrane, a $10 \mu \mathrm{m}$ thick layer composed of collagen fibrils below which is the stroma [20]. The stroma is composed of $78 \%$ water, $16 \%$ collagen fibres and quiescent keratocytes [21] and makes up $90 \%$ of the cornea [22]. The collagen fibrils (mainly collagen I) in the stroma are arranged to form lamellae and there are several lamellae that run in parallel to the corneal surface [23]. Due to the arrangement of fibrils the cornea as a whole is transparent [24]. Descemet's membrane, the basement membrane of the endothelium [25] comprises of collagen fibres [26] while the endothelium is a single layer of endothelial cells that do not proliferate once mature, even if injury has taken place [27]. However, in vitro, these cells can be cultured, which offers the opportunity to transplant cells back into the eye to restore vision [28]. The corneal endothelium has a very important pump-leak mechanism which maintains hydration of the cornea [29]. Here, solutes and fluid are pumped from the stroma into the aqueous humor while at the same time solutes and fluids leaks into of the stroma from the aqueous humor. This mechanism is driven by osmosis and prevents stromal oedema [30], thus maintaining the transparency of the cornea.

Each of these layers is responsible for the transparency and maintenance of vision. Usually loss of transparency is indicative of disruption to one or more of the corneal layers.

\subsubsection{The corneal epithelium}

The corneal epithelium is comprised of about 5-7 layers of stratified squamous, non-keratinised cells [31] and plays an important role in allowing oxygen [32] entry into the eye but at the same time prevents bacterial entry [33] which may lead to infection. The corneal epithelium consists of three layers of cells: the basal columnar monolayer, 2-3 layers of wing cells and the uppermost two to three layers of superficial cells [34]. 
The stem cells of the corneal epithelium lie in small pockets / niches about $120 \mu \mathrm{m}$ in length, popularly known as limbal stem cell niches which are present in structures known as the Palisades of Vogt [35]. The stem cells are reported to lie in the basal part of the niche, well protected from external factors, maintained by several intrinsic factors [36].

As stem cells divide, they produce one cell that remains a stem cell and a daughter cell that eventually differentiates into corneal epithelial cells [37]. The cells in the limbus (located at the periphery of the cornea) are stratified columnar, non-keratinised cells which are about 7-10 layers in thick [37]. As the daughter cells/transient amplifying cells divide they move upwards and inwards from the periphery of the cornea toward the central cornea region where they eventually terminally differentiate and are washed away with the blinking action of the eye. An equilibrium exists in the rate at which the limbal stem cells divide and the cells slough off at the central corneal region. The stem cells under normal functioning are considered to be quiescent even though there is some level of proliferation to maintain the homeostasis of the corneal epithelium [38]. However, upon the onset of injury, the stem cells switch to a highly proliferative state where they divide rapidly to heal corneal wounds, and switch back to the quiescent state once the wound has healed [36].

Apart from housing the stem cell niches, the limbus also serves as a barrier between the conjunctiva and the cornea, preventing the vascularised conjunctiva from moving on to the cornea and vascularising the region [39].

\subsubsection{Limbal stem cell deficiency}

During injury, the proliferation of the stem cells must be sufficient to prevent the conjunctival cells from encroaching into the corneal region. This may happen if the proliferation of the stem cells is slow or the stem cells are completely absent due to damage [36]. Damage to the limbus is known as limbal stem cell deficiency and may occur due to genetic diseases such as aniridia [40], thermal and chemical burns [41], extensive radiation, surgery, cryotherapy [42], inflammatory diseases such as Stevens-Johnson syndrome [43], as well as contact lens use [44]. Clinical symptoms include pain, blurred vision, tearing, inflammation and in extreme cases blindness [45]. Using impression cytology, limbal stem cell deficiency can be confirmed by identifying goblet cells [46] and cytokeratins characteristic of conjunctival cells [47].

Limbal stem cell deficiency can be divided into partial or total deficiency (Figure 3). 


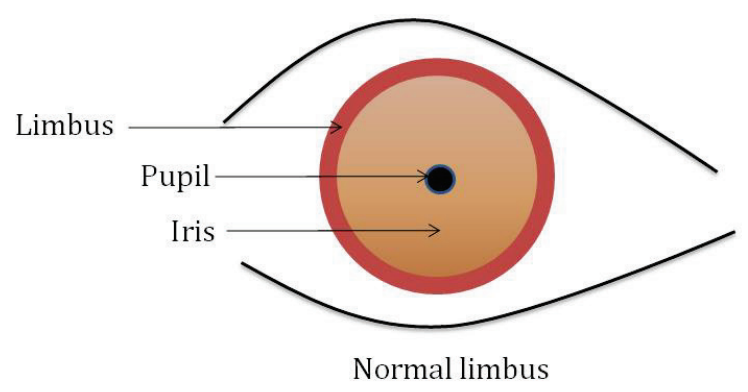

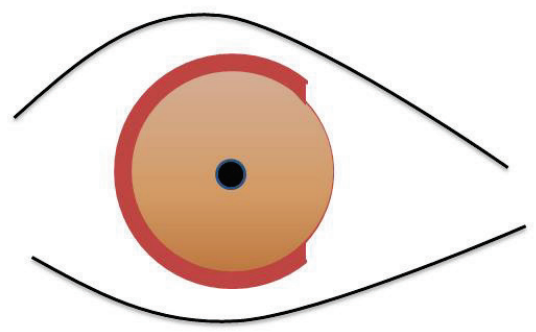

Partial limbal stem cell deficiency

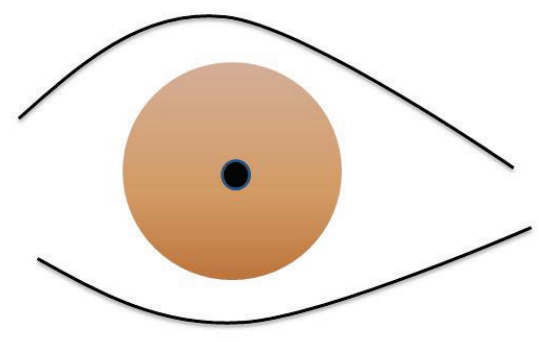

Total limbal stem cell deficiency

Figure 3. Schematic of an eye showing a normal limbus (red), partial limbal stem cell deficiency (red partly absent) and total limbal stem cell deficiency (the red is absent)

\subsubsection{Partial limbal stem cell deficiency}

When only a part of the limbus is absent, it is known as partial limbal stem cell deficiency. The disease may range from mild, where an abnormal epithelium is present on the corneal surface to severe, where vision is affected and a fibrovascular pannus is present.

The deficiency may affect vision, in which case intervention is necessary or may not affect vision, in which case minimal intervention or medication alone is necessary [45]. Surgical intervention usually involves mechanical debridement of the conjunctival cells that have moved on to the corneal region.

\subsubsection{Total limbal stem deficiency}

When the whole limbal region has been damaged or is absent, this is called total limbal stem cell deficiency. Management in this case would involve debridement of the conjunctival cells along with subsequent transplantation of a new source of limbal epithelium [5]. The source of the new epithelium could be from the patient's undamaged eye if the condition is unilateral damage; however, in the case of bilateral damage, cells are sourced from a donor [48]. Also being explored is the use of other autologous cell types which will be explained later in this chapter. 


\subsubsection{Clinical treatments of limbal stem cell deficiency}

The first successful corneal transplantation was carried out by Zirm in 1905 [49]. Due to the immune privileged nature of the cornea, it is a tissue that can be transplanted without concerns of rejection and thus there is no need for immunosuppression. Attempts have been made to transplant corneas to treat limbal stem cell deficiency; however, they have been unsuccessful as the procedure only includes the central transparent cornea and not the limbal area [48].

Because of this, over the last few decades, researchers have explored the use of several different methods to deliver fresh epithelial tissue or cultured epithelial cells to damaged corneas after mechanical debridement of the conjunctival cells.

\subsubsection{Conjunctival transplantation}

This procedure was first attempted by Thoft in 1977 [50] where he took a few pieces of bulbar conjunctiva from the healthy eye to treat unilateral limbal stem cell deficiency caused by burns. The procedure was based on conjunctival transdifferentiation. It was reported that the conjunctival cells on the cornea underwent a slow transformation into corneal epithelium-like cells, a process known as conjunctival transdifferentiation [50]. Dua studied the concept of conjunctival transdifferentiation on animals and came to the conclusion that it was unlikely that conjunctival transdifferentiation was actually taking place and it was instead squamous metaplasia with the loss of goblet cells. It was also suggested that complete damage of the limbus of the animals had not been carried out in the experiments leading to a partial limbal stem cell deficiency model [51]. This suggests that there is a possibility that even though the diagnosis of the disease was total stem cell deficiency, it may actually have been partial with the corneal epithelial cells trying to cover the corneal region.

\subsubsection{Keratoepithelioplasty}

Keratoepithelioplasty was first carried out by Thoft in 1984 [52]. This procedure was mainly targeted towards patients with bilateral damage, as the tissue transplanted was from cadaveric donors. In this treatment, the whole globe of the cadaver was taken and the partial thickness cornea was excised. The cornea was sectioned into four segments and lenticules comprising the epithelium and stroma from the mid peripheral region were excised and sutured onto the patient's damaged eyes. The vision of three out of four patients improved after the procedure; however, the procedure for the fourth patient failed due to complications [52]. Interestingly, at this time knowledge of limbal stem cells was very incomplete; it is possible that during the keratoepithelioplasty procedure, part of the limbus was excised leading to its transplantation onto the cornea [53]. 


\subsubsection{Conjunctival limbal transplantation}

This procedure was an extension of the conjunctival transplantation including a part of the limbal region along with the bulbar conjunctiva. A report of the successful use of this technique on 21 patients was pubished by Kenyon and Tseng [54]. The tissue used in this procedure was autologous tissue.

\subsubsection{Living related conjunctival limbal allograft}

This procedure was similar to conjunctival limbal transplantation except for the fact that the tissue was sourced from a living relative of the patient. This would mean the procedure could be employed for the treatment of bilateral injuries. However, in such cases, tests would need to be carried out in order to determine the human leukocyte antigen (HLA) typing of relatives to avoid rejection of the transplanted tissue [55].

\subsubsection{Keratolimbal allograft}

Keratolimbal allografts involved excising the whole limbus as one tissue from cadaver donors. The ring graft contains a very small amount of sclera, the whole limbus and the peripheral cornea. Clinical outcomes for the use of keratolimbal allografts have shown a success rate of 82-100\% after 1-2 years follow-up but a decrease to $50 \%$ after 3-5 years [56].

\subsubsection{Ex vivo expansion of limbal epithelial cells}

It has become clear over the last few decades that the transplantation of limbal epithelial cells (or limbal tissue explants) is essential to treat limbal stem cell deficiency. Especially in the case of unilateral damage, sacrificing other parts of the eye like the conjunctiva may not be necessary. Pellegrini et al. were the first to report the transplantation of a limbal epithelial sheet grown on growth arrested murine 3T3 cells onto the damaged a cornea of an eye. The group reported that this procedure was used on two patients and showed normal epithelia even after a 2 year follow up [57]. This study proved the concept that only the limbal cells were necessary to treat limbal stem cell deficiency.

In summary several treatments have been explored for the treatment of limbal stem cell deficiency using either both conjunctival cells and limbal cells or only limbal cells. Based on the knowledge we have about conjunctival cells being quite different from corneal cells, such as goblet cells, using limbal cells alone has proven to be the best option. 


\subsection{USING DIFFERENT CELL TYPES AND CARRIERS FOR LIMBAL STEM CELL TRANSPLANTATION}

Since the report of Pellegrini et al. in 1997, extensive research has been carried out to improve the technique. The use of other cell types to replace limbal stem cells has been explored for transplants involving the eye. This would be either to avoid taking a biopsy from the patient's healthy eye (in the case of unilateral damage) which may cause some damage or because healthy limbal stem cells are not available (in the case of bilateral damage). Even though the concept of transplanting a sheet of limbal epithelial cells seemed promising, handling a sheet of epithelial cells appeared to be a challenge; for this reason, researchers started to explore different carriers to assist with the transfer of limbal epithelial cells.

\subsubsection{Transplantation of different cell types}

In order to overcome the necessity of using immunosuppressants when tissue is taken from a donor for bilateral damage, the option of using the patient's own cells but from a different source has been explored. Oral mucosal cells have been cultured on either a natural [58] or synthetic [59] substrate and transplanted onto the eye. These cells are similar to limbal epithelial cells, they are stratified squamous non-keratinised cells which express CK3, P63 and ABCG2, as in corneal / limbal epithelial cells but not CK12 [60]. Clinical studies have shown that even though the oral mucosal cells improve visual acuity, there have been reports of neovascularisation at the peripheral region of the cornea [59].

Blazejewska et al. explored the use of hair follicle stem cells as an alternative to the limbal epithelial cells by culturing the cells on Laminin 5 in corneal stromal conditioned medium [61]. There was an up-regulation of CK12 and Pax6 and a down-regulation of epidermal keratinocyte marker CK10, indicating that hair follicle stem cells differentiate into corneal like cells [62]. Using an animal model of limbal epithelial stem cell deficiency, hair follicle cells were cultured on a 3T3 feeder layer after which they were placed on a fibrin carrier and transplanted onto the eye. Using this technique, an $80 \%$ success rate was achieved with the hair follicle cells differentiating into a corneal epithelial phenotype [61].

Similarly embryonic stem cells were cultured on collagen IV in limbal fibroblast-conditioned media the embryonic stem cells differentiated into corneal epithelial phenotype expressing p63 and CK3/12. CK10 was also expressed indicating that the cells also had a skin epithelial phenotype [63]. Hanson etal. demonstrated the transplantation of differentiated human embryonic cells onto corneal buttons; 6 days after transplantation Pax6 and CK3 were detected [64]. However, there have been no reports of using these techniques in the clinic as yet. 
Mesenchymal stem cells have also been studied in rabbits by performing amniotic membrane transplantation followed by injection of mesenchymal stem cells. The study resulted in cells that were positive for CK3/12, but there was no clear difference in the expression of ABCG2 between the transplanted group and the control (limbal stem cell deficient eyes), which is usually positive for limbal epithelial cells [65].

Also, sheets of dental pulp stem cells have been transplanted on to a limbal stem cell deficiency animal model and the amniotic membrane placed over the sheet. The results for mild chemical burn animal models showed less neovascularisation and expression of CK3, ABCG2 and P63, while this was not seen in the severe chemical burn models [66].

The exploration of mesenchymal and dental pulp stem cells for limbal stem cell deficiency treatment has not progressed to clinical evaluation to date.

\subsubsection{Limbal cell carriers}

\subsection{Amniotic membrane}

The amniotic membrane is the innermost layer of the foetal membrane [67] formed during the course of pregnancy. It consists of an epithelial layer, a thick basement membrane and an avascular stroma which has the ability to promote healing and exclude inflammatory cells [68].

The amniotic membrane is commonly used to deliver limbal epithelial cells to damaged corneas. It is known to preserve the stemness of cells, helps in the growth and proliferation of cells and also lacks immunogenicity [69]. It has been shown that the amniotic epithelial cells do not express HLA-A, -B, or -DR but do express HLA-G [69]; therefore using denuded amniotic membrane is preferred for transplantation [70] as it lowers the chance of rejection. Studies have shown that limbal cells grow much better on amniotic membranes denuded of their epithelium than amniotic membranes with intact epithelium [71]. In addition, using cryopreserved tissue is preferred to fresh as any amniotic epithelial cells remaining on the amniotic membrane would probably be non-viable [72].

Before using the amniotic membrane for limbal stem cell deficiency, it needs to undergo a screening process in order to lower the risk of disease transmission [73]. The process in Western countries must take place by law, with blood from the donor being screened for human immunodeficiency virus (HIV), hepatitis $\mathrm{B}$, and $\mathrm{C}$, cytomegalovirus and syphilis at the time of donation and once more after 6 months giving enough time for the donor to develop antibodies for the disease if actually infected [72]. In developing countries such screening is not yet a legal requirement [67].

Once obtained from the donor, the amniotic membrane is washed with media to remove any blood clots after which it is spread epithelial side up on a $0.22 \mu \mathrm{m}$ nitrocellulose membrane. The membrane along with the amniotic 
membrane, is placed in a container containing glycerol or dimethyl sulfoxide (DMSO) and media containing antibiotics; this is then stored at $-80{ }^{\circ} \mathrm{C}$ [74] until its use after 6 months. The amniotic membrane may also be cryopreserved, irradiated or lyophilised [75].

The amniotic membrane was first used for therapeutic purposes in 1910 by Davis for skin transplantation and for the eye by de Rotth in 1940 [76] as reported by Rahman etal. [67]. Studies have shown that the amniotic membrane can be used to treat partial limbal stem cell deficiency without the need for limbal cells [77]. The amniotic membrane possess both anti-inflammatory and anti-angiogenic properties [70], which assist in the treatment of limbal stem cell deficiency.

In the case of total limbal stem cell deficiency cells are cultured on the amniotic membrane and then transplanted to the damaged eye [77]. In some cases where the cornea is seriously damaged, corneal transplantation is carried out after limbal stem cell transplantation [78]. This method has now become the gold standard for treating total limbal stem cell deficiency [77].

Studies have shown that processing of the amniotic membrane can lead to inter-donor and intra-donor variation, as a result it has been suggested that a standard protocol [79] as well as its use [80] should be followed globally. Also, obtaining the amniotic membrane for transplantation purposes is highly dependent on donors and once obtained needs to go through a tissue bank which could take several months. Sangwan et al. reported the clinical outcome of limbal cell transplantation using the amniotic membrane on 200 patients [81]. After a one year period, the success rate was $76 \%$, dropping to $68 \%$ after 4 years. It is not known why the technique fails after several years for some patients. It could be due to an inherent condition of the patient or to the percentage of limbal stem cells transplanted or to the limbal stem cell niches not providing a long-term secure "home" for the transplanted cells. Variation in the amniotic membrane itself could also be a factor. In practice there are many factors that could affect the long-term outcome and this remains an area for research for the future [82]. Also, despite the success in using the amniotic membrane as a cell carrier, researchers are still exploring alternatives.

\subsection{Other natural polymers as a carrier}

Using natural polymers as delivery systems has been popular due to their availability.

The potential of using recombinant highly cross linked collagen scaffolds to culture limbal epithelial cells has been explored. The study showed that the cells maintained their stem cell properties and also could differentiate into corneal epithelial cells upon stratification [83]. However, there have been no reports on clinical studies using this approach as yet. Levis et al. studied the use of plastic compressed collagen I from rat tail to deliver cells to the cornea and showed that the cells cultured on the compressed collagen resembled 
those on native central cornea and could possibly be used as an alternative to the amniotic membrane. However there is no indication on whether, if taken to the clinic, a recombinant form of collagen will be used or not [84].

Rama et al. explored the use of autologous fibrin as a cell carrier for limbal stem cell transplantation (clinically known as Holoclar ${ }^{\circledR}$ ). A clinical study using this method to transfer the cells showed that the technique was successful in $76.6 \%$ of the patients after a 10 year period and all failures occurred within the first year after surgery [85]. Last year, Holoclar ${ }^{\circledR}$ was given the go ahead by the European Medicines Agency to be used in the clinic, becoming the first stem cell-based medicinal product approved in the Western world. The approval of this product is an assurance to other stem cell researchers that there is some chance that the novel techniques that are being developed for treatment could reach the clinic.

Culture of limbal epithelial cells on Bombyx mori silk fibroin films [86] and chitosan-gelatine membranes [87] have also been studied as alternatives to the amniotic membrane. The stem cell properties and the potential to differentiate into corneal epithelial cells were maintained in these studies with the films / membranes being easy to handle, similar to the amniotic membrane.

The anterior lens capsule has also been studied as a cell carrier system. Anterior lens capsules were removed from patients during cataract surgery and were processed to remove the crystalline epithelium. Limbal biopsies from the patients were cultured on the capsule (limbal biopsy and capsule from the same eye - autologous; limbal biopsy and capsule from two different eyes-allogenic) showed that limbal cells which migrated out from limbal explants could be cultured on the capsules under both autologous and allogeneic conditions with a cell viability of $>95 \%$ [88].

\subsection{Synthetic polymers as a carrier}

The use of synthetic polymers has also been an option to develop cell carrier systems. Natural polymers need to be isolated from human / animal tissue and can be inherently variable;by using synthetic polymers this can be avoided.

A temperature-responsive polymer, poly( $N$-isopropylacrylamide) has been used clinically by Nishida's group. This polymer which changes its hydration with temperature has been used to culture limbal epithelial cells [89], as well as oral mucosal cells [59]. Cells were cultured on the temperature-sensitive polymer at $37^{\circ} \mathrm{C}$ for 2 weeks after which the temperature was reduced to $30^{\circ} \mathrm{C}$. This caused the polymer to swell, releasing the sheet of cells without using any proteases, to be transferred onto the damaged eye [59]. These methodologies allow the initial production of sheets of cells but these delicate cell sheets must then be transferred to the cornea.

Another temperature-sensitive polymer has been explored as a carrier for limbal cells, Melbiol, a thermoresponsive polymer block $[\operatorname{poly}(N-$ -isopropylacrylamide-co-n-butyl methacrylate) (poly(NIPAAm-co-BMA)] and 
the hydrophilic polymer block [poly(ethylene glycol) (PEG)]. Similar to Nishida's work [59], cells were cultured on the Mebiol gel surface at $37^{\circ} \mathrm{C}$; after 3 weeks, the temperature was dropped to $4{ }^{\circ} \mathrm{C}$ releasing the sheet of cells [90]. Cells cultured on the gel showed expression of ABCG2, P63 as well as CK3 [91]. Animal studies using the gel were carried out showing a $58 \%$ total and $17 \%$ partial success rate [90].

Contact lenses have been used as a delivery system for limbal epithelial cells. Di Girolamo et al. explored the use of lotrafilcon A contact lenses to culture limbal epithelial cells [92]. Most recent clinical studies using the contact lens to deliver the cells to the cornea showed a $63 \%$ success rate after a 2.5 year median follow-up period [93]. Deshpande et al. coated a commercially available contact lens with acrylic acid using plasma polymerisation. This surface supported the attached of limbal epithelial cells but over a period of time the surface degraded releasing the cells on the surface of an ex vivo rabbit cornea model [94]. Similar studies using plasma coated lenses have been explored by other groups [95] including animal studies on rabbits [96]. Here, a model of limbal stem cell deficiency was created on the rabbit eyes and the acrylic acid coated lenses along with the limbal epithelial cells were transferred onto the model. Twenty six days after transplantation a stratified epithelium had formed on the surface of the rabbit eye. After staining the cells on the contact lens with BrdU prior to transplantation, results showed that some cells in the basal and suprabasal layers of the stratified epithelium post transfer retained BrdU suggesting the maintenance of highly proliferating cells after such a procedure [96].

Another popular technique in the field of tissue engineering is the use of electrospun scaffolds as these can resemble the structure of the extracellular matrix [97]. Electrospinning is based on electrostatic forces, where a highly charged polymer jet falls towards an oppositely charged or earthed surface (the collector). As the polymer jet falls onto the collector, the solvent evaporates, leaving fibres of the polymer to make up the scaffold. In order to achieve reproducibility, the technique must be carried out using constant parameters in particular, voltage, temperature, humidity, flow rate of polymer jet, distance from needle to the collector and concentration. These parameters can control fibre diameter, whole scaffold thickness, orientation of the fibres and pore size all which affect the degradation rate, if a biodegradable polymer is spun. Electrospun scaffolds can be spun as random [98], aligned [99] or even diagonal mats of fibres [100].

The choice of the polymer and solvent also is highly dependent on the type of scaffold required; for example, dissolving $10 \%$ poly( $\varepsilon$-caprolactone) in glacial acetic acid, $90 \%$ acetic acid, methylene chloride (MC) / Dichloroformamide (DMF) (4/1), glacial formic acid, and formic acid/acetone (4/1) at a constant voltage, distance to collector and flow rate, resulted in nanofibres with spindle like beads when dissolved in both glacial acetic acid and $90 \%$ acetic acid. In MC / DMF, a mixture of micro and nanofibres was observed with 
no beads, in glacial formic acid, brittle nanofibres were observed again with no beads, and in formic acid and acetone, branched nanofibres were noted along with many beads [101].

Electrospun scaffolds are being used for ophthalmology [102], skin [103], spinal cord [104] and bone [105]. With respect to limbal stem cell deficiency, electrospun scaffolds are being explored as an alternative to the amniotic membrane. A study by Deshpande et al. has used poly(lactide-co-glycolide) (PLGA) electrospun scaffolds (Figure 4) to culture limbal epithelial cells along with an ex vivo rabbit cornea model. The study showed the transfer of cells from the biodegradable electrospun scaffold to the rabbit after 4 weeks in culture. The cells cultured on the scaffold and those that transferred from the scaffold onto the cornea model expressed CK3 and P63. Additionally, in this study, outgrowth of limbal epithelial cells from corneal limbal explants was demonstrated, showing that limbal epithelial cells grew out from the explants and also transferred successfully to an ex vivo rabbit cornea model. These in vitro studies also showed that these scaffolds degraded within weeks and could be terminally sterilized using gamma irradiation and stored for long periods if kept dry and cold [98].

Sharma et al. have also used poly( $\varepsilon$-caprolactone) electrospun scaffolds to support limbal epithelial cell growth. The cells on the scaffold expressed CK3/12, Integrin $\beta 1$ and ABCG2 [106]. On plasma coating the scaffold with helium-oxygen, studies showed that there was an improvement in the cell attachment and proliferation [107]; however, no transfer studies have yet been reported with this membrane.
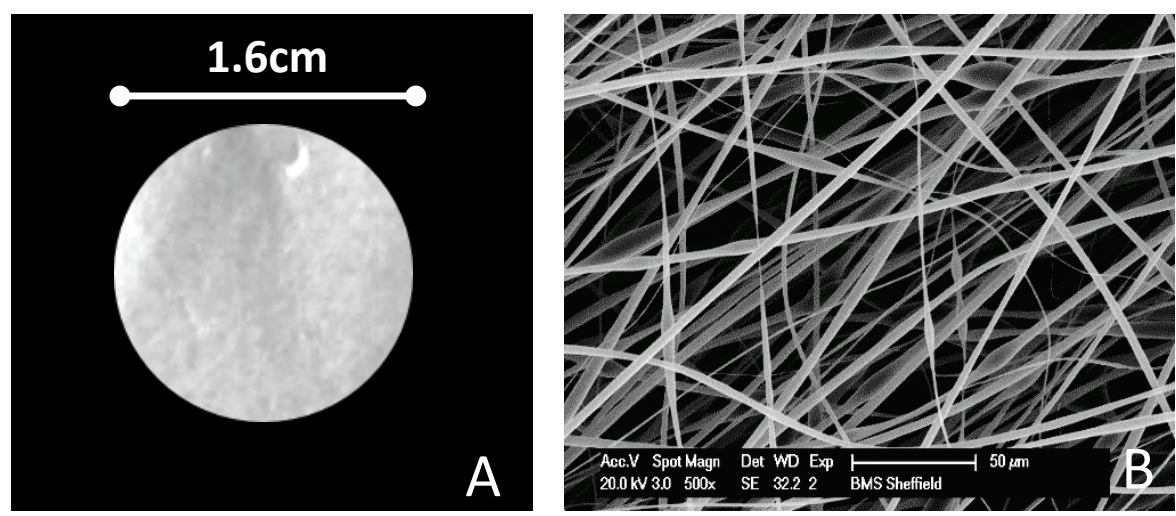

Figure 4. (A) Photograph and (B) scanning electron microscope (SEM) of the PLGA electrospun scaffold used to transfer cells onto an ex vivo rabbit cornea model

Ortega et al. [108] went one step further and introduced micro-pockets within PLGA electrospun scaffolds similar to those used by Deshpande et al. [98]. 
Using a combination of microstereolithography and electrospinning to develop a template, an electrospun scaffold was fabricated with small pockets at the periphery (Figure 5) that could potentially house stem cells. The long-term failure of limbal stem cell transplantation could be due to the fact that the stem cells that are transplanted back onto the eye are not well protected. The technique described by Ortega etal. opens up the possibility of keeping the limbal tissue explants well protected from the external environment within the micro-pockets, as the pockets act as artificial stem cell niches [109].
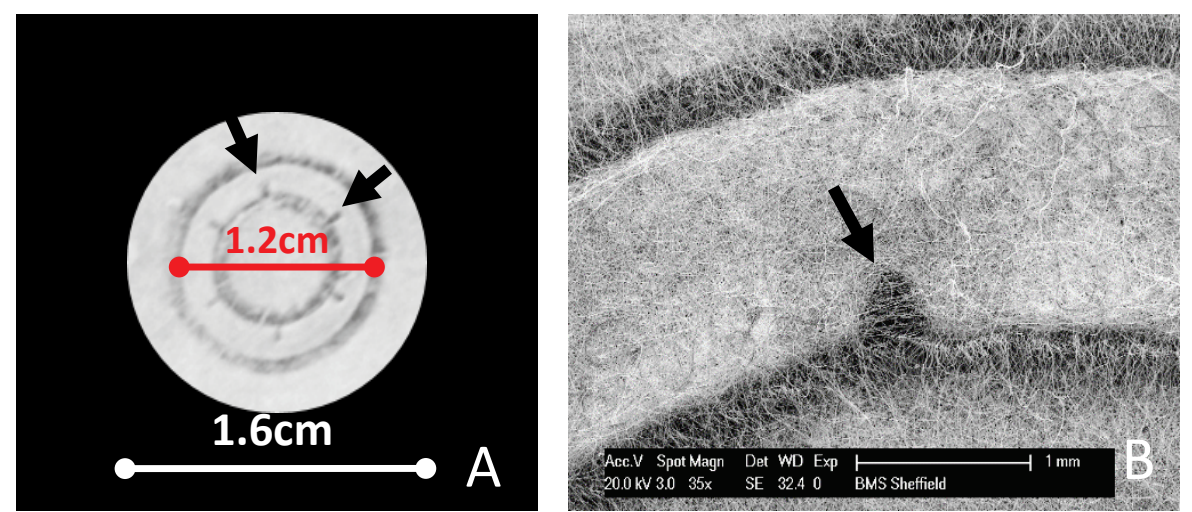

Figure 5. (A) Photograph and (B) SEM of PLGA electrospun scaffold with micropockets (indicated by arrows)

The cell carrier used to transplant cells is of utmost importance as it needs to support the initial cell growth as well as release cells onto the cornea in a controlled manner. As explained, several different techniques have been explored for more than a decade and there appear to be several that work clinically. It is not yet clear whether any will prove better than the others in terms of consistency of delivery of cells or long-term outcomes. With the approval of the Holoclar ${ }^{\circledR}$ system by the European Medicines Agency, it is just a matter of time until the outcome of the technique is revealed on a larger number of patients and the way is paved for other techniques to be introduced to the market.

An overview of the cells and substrates used to treat limbal stem cell deficiency is summarized in Figure 6. 

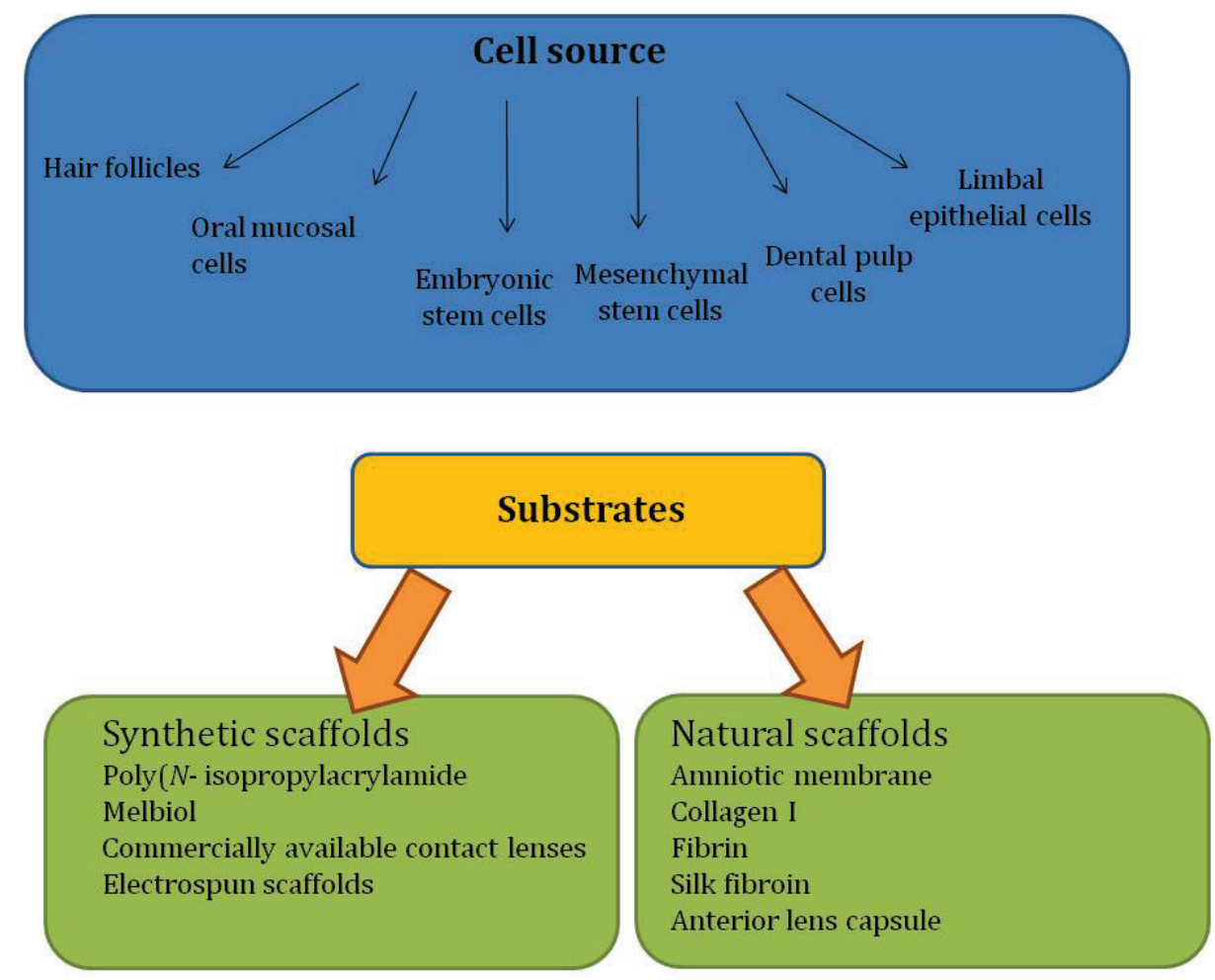

Figure 6. Schematic of the different cell sources and different substrates used to treat limbal stem cell deficiency

\subsection{NANOMATERIALS FOR OCULAR REPAIR}

Nanotechnology is the engineering of material at a submicron scale [110] and a quite common use of nanotechnology is drug delivery, where drugs are incorporated into nanoparticles [111]. Nanotechnology is also broadly used in tissue engineering applications for cell delivery, for example, by using nanofibrous scaffolds for cell delivery purposes.

Studies have shown that neural stem cell differentiation was higher on nanofibrous electrospun scaffolds compared to microfibrous scaffolds [112]. Some groups have fabricated the nanofibrous scaffolds so that cell penetration is not possible due to the presence of nanopores preventing the cells from moving into the scaffold. This encourages cross talk between the cells on the nanofibrous scaffold surface and any other cells that are present in the culture system but not in direct contact.

Over the last few years, researchers have started to use nanotechnology to treat ocular diseases in the form of nanoparticles [113] and nanofibrous 
scaffolds [106]. Nanoparticles have mainly been used for drug delivery such as in the case of PLGA loaded with pirfenidone introduced to an alkali burn rat model. In this study, loading the drug into nanoparticles significantly decreased collagen production, haze and increased corneal re-epithelisation [114]. Also the use of silicate nanoparticles to provide an anti-angiogenic effect on corneal vascularisation has been explored [113]. Figure 7 gives an overview of the use of nanotechnology to treat diseases of the cornea.

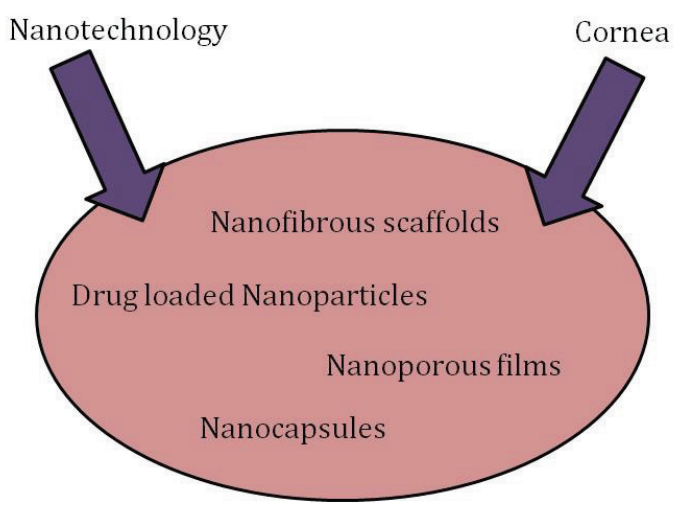

Figure 7. Schematic showing the use of nanotechnology in the treatment of diseases of the cornea

With respect to delivering cells for treatment of limbal stem cell deficiency, some studies have employed the use of nanofibrous electrospun scaffolds as an alternative to the amniotic membrane under in vitro conditions[115]. This may be similar to culturing limbal cells on the amniotic membrane as the cells do not penetrate into the membrane and remain on the surface [116] unlike when microfibrous scaffolds are used [98]. Low et al. studied the use of thermally-oxidised, aminosilanised porous silicon membranes with nanopores as another alternative to the amniotic membrane. The study showed that the limbal epithelial cells cultured on these silicon membranes expressed both CK3/12 and P63 and using these nanoporous membrane increases the surface area and improves cellular contact with the physiological environment, while at the same time supporting cell attachment [117]. Another interesting study explored the use of a gel that contains self-assembled nanocapsules of chitosan to support the culture of keratocyte reprogrammed induced pluripotent stem cells (iPSCs). Using a limbal stem cell deficiency rat model, the iPSCs combined with the nanogel showed restoration of the corneal epithelium [118]. 


\subsection{EXPANSION OF CELLS ON THE CARRIER}

A problem using the above techniques which has not been given enough importance has been expanding the cells on the carriers before transplantation. Once a limbal biopsy is obtained from the patient's healthy eye (in the case of unilateral damage), the common method is to place the pieces of the limbal biopsy ( $\sim 500 \mu \mathrm{m}$ in size) on the amniotic membrane (for example) and allow the cells to migrate out onto the membrane over 7-10 days [119]. Cleanrooms are extremely expensive to set up and run and such facilities are usually only available in specialized hospitals in urban areas in developing countries [120]. In order to overcome the inconvenience and costs, Sangwan etal. developed the technique of simple limbal epithelial transplantation (SLET) [121]. Here, limbal explants from the healthy eye (in the case of unilateral damage) were finely dissected and fibrin glued onto the amniotic membrane in theatre and placed on the patient's eye in one operation. This obviates the need to expand the cells in the expensive-to-run cleanrooms [122]. The first clinical study of six patients showed a $100 \%$ success rate 6 weeks after surgery which was maintained after 9 months [121]. Longer term studies are in progress (personal communication). A similar approach was proposed in the study of Deshpande et al. to use limbal tissue explants with a synthetic biodegradable electrospun PLGA membrane [98]. This technique needs to be evaluated clinically, but if successful, would then allow surgeons to take an "off-the-shelf" sterilised, prepacked membrane and combine it with limbal tissue explants in theatre, obviating the need for access to clean room facilities or to tissue banks to supply amniotic membrane. [123].

\subsection{CONCLUSIONS}

Where diseases of the cornea result in limbal stem cell deficiency there are now a small number of centres (estimated at 10 at the time of writing) worldwide with expertise in using cell therapy and a range of delivery membranes to treat limbal stem cell deficiency. The challenge is to make this technology, which is very successful at least in the short-term, available to more surgeons and hence more patients worldwide.

The exploration of nanotechnology in treating diseases of the cornea has recently started and has a promising future. Thus, drug delivery via nanotechnology in corneal diseases has reached the stage of animal experimentation but has not yet been trialled clinically. 


\section{REFERENCES}

1. P. Macchiarini, P. Jungebluth, T. Go, M.A. Asnaghi, L.E. Rees, T.A. Cogan, A. Dodson, J. Martorell, S. Bellini, P.P. Parnigotto, S.C. Dickinson, A.P. Hollander, S. Mantero, M.T. Conconi, M.A. Birchall. Lancet 372 (2008) 2023-2030.

2. A.M. Raya-Rivera, D. Esquiliano, R. Fierro-Pastrana, E. Lopez-Bayghen, P. Valencia, R. Ordorica-Flores, S. Soker, J.J. Yoo, A. Atala. Lancet 384 (2014) 329-336.

3. M. Moustafa, C. Simpson, M. Glover, R.A. Dawson, S. Tesfaye, F.M. Creagh, D. Haddow, R. Short, S. Heller, S. MacNeil. Diabet. Med. 21 (2004) 786-789.

4. S. Bhargava, J.M. Patterson, R.D. Inman, S. MacNeil, C.R. Chapple. Eur. Urol. 53 (2008) 1263-1269.

5. H.S. Dua, A. Azuara-Blanco. Br. J. Ophthalmol. 83 (1999) 414-419.

6. E.A. Ryan, B.W. Paty, P.A. Senior, D. Bigam, E. Alfadhli, N.M. Kneteman, R.T.J. Lakey, A.M.J. Shapiro. Diabetes 54 (2005) 2060-2069.

7. P. Deshpande, D.R. Ralston, S. MacNeil. Burns 39 (2013) 1170-1177.

8. S.K. Goh, S. Bertera, P. Olsen, J.E. Candiello, W. Halfter, G. Uechi, M. Balasubramani, S. Johnson, B. Sicari, E. Kollar, S.F. Badylak, I. Banerjee. Biomaterials 34 (2013) 6760-6772.

9. $\quad$ D.G. Wallace, J. Rosenblatt. Adv. Drug Deliv. Rev. 55 (2003) 1631-1649.

10. E.S. Place, J.H. George, C.K. Williams, M.M. Stevens. Chem. Soc. Rev. 38 (2009) 1139-1151.

11. P. Gentile, V. Chiono, F. Boccafoschi, F. Baino, C. Vitale-Brovarone, E. Verne, N. Barbani, G. Ciardelli. J. Biomater. Sci. Polym. Ed. 21 (2010) 1207-1226.

12. S. Rimmer, C. Johnson, B. Zhao, J. Collier, L. Gilmore, S. Sabnis, P. Wyman, C. Sammon, N.J. Fullwood, S. Macneil. Biomaterials 28 (2007) 5319-5331.

13. K.A. Blackwood, R. McKean, I. Canton, C.O. Freeman, K.L. Franklin, D. Cole, I. Brook, P.M. Farthing, S. Rimmer, J.W. Haycock, A. Ryan, S. Macneil. Biomaterials 29 (2008) 3091-3104.

14. J. Morales Pedraza, M. Herson. Cell Tissue Bank. 13 (2012) 103-117.

15. J.J. Doutch, A.J. Quantock, N.C. Joyce, K.M. Meek. Biophys. J. 102 (2012) 1258-1264.

16. B.K. Ambati, M. Nozaki, N. Singh, A. Takeda, P.D. Jani, T. Suthar, R.J. Albuquerque, E. Richter, E. Sakurai, M.T. Newcomb, M.E. Kleinman, R.B. Caldwell, Q. Lin, Y. Ogura, A. Orecchia, D.A. Samuelson, D.W. Agnew, J. St Leger, W.R. Green, P.J. Mahasreshti, D.T. Curiel, D. Kwan, H. Marsh, S. Ikeda, L.J. Leiper, J.M. Collinson, S. Bogdanovich, T.S. Khurana, M. Shibuya, M.E. Baldwin, N. Ferrara, H.P. Gerber, S. De Falco, J. Witta, J.Z. Baffi, B.J. Raisler, J. Ambati. Nature 443 (2006) 993-997.

17. D.C. Beebe. Semin. Cell Dev. Biol. 19 (2008) 125-133.

18. C. Cursiefen, U. Schlötzer-Schrehardt, M. Küchle, L. Sorokin, S. Breiteneder-Geleff, K. Alitalo, D. Jackson. Invest. Ophthalmol. Vis. Sci. 43 (2002) 2127-2135.

19. J. Zhao, V. Mo, T. Nagasaki. J. Histochem. Cytochem. 57 (2009) 177-185.

20. N. Pinnamaneni, J.L. Funderburgh. Stem cells 30 (2012) 1059-1063.

21. L.A. Pruitt, A.M. Chakravartula, Mechanics of Biomaterials: Fundamental Principles for Implant Design, Cambridge University Press, 2011.

22. J.A. West-Mays, D.J. Dwivedi. Int. J. Biochem. Cell Biol. 38 (2006) 1625-1631.

23. A. Daxer, P. Fratzl. Invest. Ophthalmol. Vis. Sci. 38 (1997) 121-129. 
24. D.M. Maurice. J. Physiol. 136 (1957) 263-286.

25. M.C. Kenney, P.D. Benya, M.E. Nimni, R.E. Smith. Invest. Ophthalmol. Vis. Sci. 18 (1979) 527-532.

26. S.G. Levy, J. Moss, H. Sawada, P.J.C. Dopping-Hepenstal, A.C.E. McCartney. Curr. Eye Res. 15 (1996) 45-52.

27. N.C. Joyce. Proliferative capacity of the corneal endothelium. Prog. Retin. Eye Res. 22 (2003) 359-389.

28. S.P. Patel, W.M. Bourne. Invest. Ophthalmol. Vis. Sci. 50 (2009) 2742-2746.

29. W.M. Bourne. Trans. Am. Ophthalmol. Soc. 96 (1998) 229-239.

30. M.R. O'Neal, K.A. Polse. Invest. Ophthalmol. Vis. Sci. 26 (1985) 849-856.

31. D.Z. Reinstein, T.J. Archer, M. Gobbe, R.H. Silverman, D.J. Coleman. J. Refract. Surg. 24 (2008) 571-581.

32. I. Fatt, M.T. Bieber. Exp. Eye Res. 7 (1968) 103-112.

33. S. Kinoshita, W. Adachi, C. Sotozono, K. Nishida, N. Yokoi, A.J. Quantock, K. Okubo. Prog. Retin. Eye Res. 20 (2001) 639-673.

34. N. Ehlers, S. Heegaard, J. Hjortdal, A. Ivarsen, K. Nielsen, J.U. Prause. Acta Ophthalmol. 88 (2010) 858-861.

35. W. Li, Y Hayashida, Y.-T. Chen, S.C.G. Tseng. Cell Res. 17 (2007) 26-36.

36. M.A. Stepp, J.D. Zieske. Ocul. Surf. 3 (2005) 15-26.

37. H.S. Dua, J.S. Saini, A. Azuara-Blanco, P. Gupta. Indian J. Ophthalmol. 48 (2000) 83-92.

38. R.A. Thoft, J. Friend. Invest. Ophthalmol. Vis. Sci. 24 (1983) 1442-1443.

39. H.S. Dua, A Azuara-Blanco. Surv. Ophthalmol. 44 (2000) 415-425.

40. K. Ramaesh, T. Ramaesh, G.N. Dutton, B. Dhillon. Int. J. Biochem. Cell Biol. 37 (2005) 547-557.

41. D. Meller, R.T. Pires, R.J. Mack, F. Figueiredo, A. Heiligenhaus, W.C. Park, P. Prabhasawat, T. John, S.D. McLeod, K.P. Steuhl, S.C. Tseng. Ophthalmology 107 (2000) 980-989.

42. S. Ahmad. Stem Cells Transl. Med. 1 (2012) 110-115.

43. J.A. Gomes, M.S Santos, A.S. Ventura, W.B. Donato, M.C. Cunha, A.L. Hofling-Lima. Arch. Ophthalmol. 121 (2003) 1369-1374.

44. C.C. Chan, E.J. Holland. Am. J. Ophthalmol. 155 (2013) 544-549.

45. H.S. Dua, A. Joseph, V.A. Shanmuganathan, R.E. Jones. Eye 17 (2003) 877-885.

46. V. Puangsricharern, S.C. Tseng. Ophthalmology 102 (1995) 1476-1485.

47. I. Garcia, J. Etxebarria, A. Boto-de-Los-Bueis, D. Diaz-Valle, L. Rivas, I. Martinez-Soroa, N. Saenz, C. López, A. Del-Hierro-Zarzuelo, R. Méndez, J. Soria, N. González, T. Suárez, A. Acera. Ophthalmology 119 (2012) 923-929.

48. S. Burman, V. Sangwan. Clin. Ophthalmol. 2 (2008) 489-502.

49. W.J. Armitage, A.B. Tullo, D.F.P. Larkin. Br. J. Ophthalmol. 90 (2006) 1222-1223.

50. R.A. Thoft. Arch. Ophthalmol. 95 (1977) 1425-1427.

51. H. Dua. Br. J. Ophthalmol. 82 (1998) 1407-1411.

52. R.A. Thoft. Am. J. Ophthalmol. 97 (1984) 1-6.

53. E. Holland, G. Schwartz. Ocular Surface Disease Medical and Surgical Management, Springer, New York, USA, 2002, pp. 149-157.

54. K.R. Kenyon, S.C. Tseng. Ophthalmology 96 (1989) 709-722.

55. P. Bakhtiari, A. Djalilian. Middle East Afr. J. Ophthalmol. 17 (2010) 9-14.

56. E.M. Espana, M. Di Pascuale, M. Grueterich, A. Solomon, S.C.G. Tseng. Eye 18 (2004) 406-417. 
57. G. Pellegrini, C.E. Traverso, A.T. Franzi, M. Zingirian, R. Cancedda, M. De Luca. Lancet 349 (1997) 990-993.

58. T. Nakamura, T. Inatomi, C. Sotozono, T. Amemiya, N. Kanamura, S. Kinoshita. Br. J. Ophthalmol. 88 (2004) 1280-1284.

59. K. Nishida, M. Yamato, Y. Hayashida, K. Watanabe, K. Yamamoto, E. Adachi, S. Nagai, A. Kikuchi, N. Maeda, H. Watanabe, T. Okano, Y. Tano.

N. Engl. J. Med. 351 (2004) 1187-1196.

60. S. Krishnan, G.K. Iyer, S. Krishnakumar. Indian J. Med. Res. 131 (2010) 422-428.

61. EA Meyer-Blazejewska, MK Call, O Yamanaka, H Liu, U Schlötzer-Schrehardt, F.E. Kruse, W.W. Kao. Stem cells 29 (2011) 57-66.

62. E.A. Blazejewska, U. Schlötzer-Schrehardt, M. Zenkel, B. Bachmann, E. Chankiewitz, C. Jacobi, F.E. Kruse. Stem Cells 27 (2009) 642-652.

63. S. Ahmad, R. Stewart, S. Yung, S. Kolli, L. Armstrong, M. Stojkovic, F. Figueiredo, M. Lako. Stem Cells 25 (2007) 1145-1155.

64. C. Hanson, T. Hardarson, C. Ellerstrom, M. Nordberg, G. Caisander, M. Rao, J. Hyllner, U. Stenevi. Acta Ophthalmol. 91 (2013) 127-130.

65. H. Reinshagen, C. Auw-Haedrich, R.V. Sorg, D Boehringer, P. Eberwein, J. Schwartzkopff, R. Sundmacher, T. Reinhard. Acta Ophthalmol. 89 (2011) 741-748.

66. J.Á.P. Gomes, B. Geraldes Monteiro, G.B. Melo, R.L. Smith, M. Cavenaghi Pereira da Silva, N.F. Lizier, A. Kerkis, H. Cerruti, I. Kerkis. Invest. Ophthalmol. Vis. Sci. 51 (2010) 1408-1414.

67. I. Rahman, D.G. Said, V.S. Maharajan, H.S. Dua. Eye 23 (2009) 1954-1961.

68. M. Dogru, M. Yildiz, M. Baykara, H. Ozcetin, H. Erturk. Eye 17 (2003) 139-148.

69. M. Kubo, Y. Sonoda, R. Muramatsu, M. Usui. Invest. Ophthalmol. Vis. Sci. 42 (2001) 1539-1546.

70. Y. Hao, D.H. Ma, D.G. Hwang, W.S. Kim, F. Zhang. Cornea 19 (2000) 348-352.

71. N. Koizumi, N.J. Fullwood, G. Bairaktaris, T. Inatomi, S. Kinoshita, A.J. Quantock. Invest. Ophthalmol. Vis. Sci. 41 (2000) 2506-2513.

72. H. Niknejad, H. Peirovi, M. Jorjani, A. Ahmadiani, J. Ghanavi, A.M. Seifalian. Eur. Cell Mater. 15 (2008) 88-99.

73. P.J. Adds, C.J. Hunt, J.K.G. Dart. Br. J. Ophthalmol. 85 (2001) 905-907.

74. H.S Dua. Br. J. Ophthalmol. 83 (1999) 748-752.

75. H.N. Madhavan, K. Priya, J. Malathi, P.R. Joseph. Indian J. Ophthalmol. 50 (2002) 227-231.

76. A. de Rotth. Arch. Ophthalmol. 23 (1940) 522-525.

77. S.G. Tseng, P. Prabhasawat, K. Barton, T. Gray, D. Meller. Arch. Ophthalmol. 116 (1998) 431-441.

78. V.S. Sangwan, M. Fernandes, A.K. Bansal, G.K. Vemuganti, G.N. Rao. Indian J. Ophthalmol. 53 (2005) 31-35.

79. A. Hopkinson, R.S. McIntosh, P.J. Tighe, D.K. James, H.S. Dua. Invest. Ophthalmol. Vis. Sci. 47 (2006) 4316-4322.

80. V.S. Maharajan, V. Shanmuganathan, A. Currie, A. Hopkinson, A. Powell-Richards, H.S. Dua. Clin. Exp. Ophthalmol. 35 (2007) 140-147.

81. V.S. Sangwan, S. Basu, G.K. Vemuganti, K. Sejpal, S.V. Subramaniam, S. Bandyopadhyay, S. Krishnaiah, S. Gaddipati, S. Tiwari, D. Balasubramanian. Br. J. Ophthalmol. 95 (2011) 1525-1529. 
82. V.S. Sangwan, R. Jain, S. Basu, A.B. Bagadi, S. Sureka, I. Mariappan, S. Macneil. Indian J. Ophthalmol. 62 (2014) 29-40.

83. S. Dravida, S. Gaddipati, M. Griffith, K. Merrett, S. Lakshmi Madhira, V.S. Sangwan, G.K. Vemuganti. J. Tissue Eng. Regen. Med. 2 (2008) 263-271.

84. H.J. Levis, R.A. Brown, J.T. Daniels. Biomaterials 31 (2010) 7726-7737.

85. P. Rama, S. Matuska, G. Paganoni, A. Spinelli, M. De Luca, G. Pellegrini. N. Engl. J. Med. 363 (2010) 147-155.

86. J. Liu, B.D. Lawrence, A. Liu, I.R. Schwab, L.A. Oliveira, M.I. Rosenblatt. Invest. Ophthalmol. Vis. Sci. 53 (2012) 4130-4138.

87. A. de la Mata, T. Nieto-Miguel, M. Lopez-Paniagua, S. Galindo, M.R. Aguilar, L. Garcia-Fernandez, S. Gonzalo, B. Vázquez, J. San Roman, R.M. Corrales, M. Calonge. J. Mater. Sci. Mater. Med. 24 (2013) 2819-2829.

88. A. Galal, J.J. Perez-Santonja, J.L. Rodriguez-Prats, M. Abad, J. Alio. Cornea 26 (2007) 473-478.

89. K. Nishida, M. Yamato, Y. Hayashida, K. Watanabe, N. Maeda, H. Watanabe, K. Yamamoto, S. Nagai, A. Kikuchi, Y. Tano, T. Okano. Transplantation 77 (2004) 379-385.

90. G. Sitalakshmi, B. Sudha, H.N. Madhavan, S. Vinay, S. Krishnakumar, Y. Mori, H. Yoshioka, S. Abraham. Tissue Eng. Part A 15 (2009) 407-415.

91. B. Sudha, H.N. Madhavan, G. Sitalakshmi, J. Malathi, S. Krishnakumar, Y. Mori, H. Yoshioka, S. Abraham. Indian J. Med. Res. 124 (2006) 655-664.

92. N. Di Girolamo, J. Chui, D. Wakefield, M.T. Coroneo. Br. J. Ophthalmol. 91 (2007) 459-464.

93. S. Bobba, S. Chow, S.L. Watson, N. Di Girolamo. Stem Cell Res. Ther. 6 (2015).

94. P. Deshpande, M. Notara, N. Bullett, J.T. Daniels, D.B. Haddow, S. MacNeil. Tissue Eng. Part A 15 (2009) 2889-2902.

95. H. Zhang, K.D. Brown, S.P. Lowe, G.S. Liu, D. Steele, K. Abberton, D. Mark. Tissue Eng. Part A 20 (2014) 1593-1602.

96. K.D. Brown, S. Low, I. Mariappan, K.M. Abberton, R. Short, H. Zhang, S. Maddileti, V. Sangwan, D. Steele, M. Daniell. Tissue Eng. Part A 20 (2014) 646-655.

97. Y.Z. Zhang, B. Su, J. Venugopal, S. Ramakrishna, C.T. Lim. Int. J. Nanomed. 2 (2007) 623-638.

98. P. Deshpande, C. Ramachandran, F. Sefat, I. Mariappan, C. Johnson, R. McKean, M. Hannah, V.S. Sangwan, F. Claeyssens, A.J. Ryan, S. MacNeil. Biomaterials 34 (2013) 5088-5106.

99. R.M. Delaine-Smith, N.H. Green, S.J. Matcher, S. MacNeil, G.C. Reilly. PLoS ONE 9 (2014) e89761.

100. W.E. Teo, M. Kotaki, X.M. Mo, S. Ramakrishna. Nanotechnology 16 (2005) 918.

101. A.G. Kanani, S.H. Bahrami. J. Nanomat. 2011 (2011) ID 724153, 10 pages.

102. S. Zhong, W.E. Teo, X. Zhu, R. Beuerman, S. Ramakrishna, L.Y. Yung. Biomacromolecules 6 (2005) 2998-3004.

103. K. Sharma, A. Bullock, D. Ralston, S. MacNeil. Burns 40 (2014) 957-965.

104. C. Liu, Y. Huang, M. Pang, Y. Yang, S. Li, L. Liu, T. Shu, W. Zhou, X. Wang, L. Rong, B. Liu. PLoS One 10 (2015) e0117709.

105. G. Tetteh, A.S. Khan, R.M. Delaine-Smith, G.C. Reilly, I.U. Rehman. J. Mech. Behav. Biomed. Mater. 39 (2014) 95-110.

106. S. Sharma, S. Mohanty, D. Gupta, M. Jassal, A.K. Agrawal, R. Tandon. Mol. Vis. 17 (2011) 2898-2910. 
107. S. Sharma, D. Gupta, S. Mohanty, M. Jassal, A.K. Agrawal, R. Tandon. Invest. Ophthalmol. Vis. Sci. 55 (2014) 899-907.

108. I. Ortega, A.J. Ryan, P. Deshpande, S. MacNeil, F. Claeyssens. Acta Biomater. 9 (2013) 5511-5520.

109. I. Ortega, P. Deshpande, A.A. Gill, S. MacNeil, F. Claeyssens. Biofabrication 5 (2013) 025008.

110. O.C. Farokhzad, R. Langer. ACS Nano 3 (2009) 16-20.

111. F.Q. Hu, Y. Hong, H. Yuan. Int. J. Pharm. 273 (2004) 29-35.

112. F. Yang, R. Murugan, S. Wang, S. Ramakrishna. Biomaterials 26 (2005) 2603-2610.

113. M. Mohammadpour, M. Jabbarvand, E. Delrish, A. Khoshzaban. J. Med. Hypotheses Ideas 8 (2014) 14-20.

114. S. Chowdhury, R. Guha, R. Trivedi, U.B. Kompella, A. Konar, S. Hazra. PLoS One 8 (2013) e70528.

115. V. Holan, A. Zajicova, A. Lencova, K. Pokorna, E. Svobodova, M. Krulova. Acta. Ophthalmol. 87 (2009) 0.

116. J. Shimazaki, M. Aiba, E. Goto, N. Kato, S. Shimmura, K. Tsubota. Ophthalmology 109 (2002) 1285-1290.

117. S.P. Low, N.H. Voelcker, L.T. Canham, K.A. Williams. Biomaterials 30 (2009) 2873-2880.

118. Y. Chien, Y.W. Liao, D.M. Liu, H.L. Lin, S.J. Chen, H.L. Chen, C.H. Peng, C.M. Liang, C.Y. Mou, S.H. Chiou. Biomaterials 33 (2012) 8003-8016.

119. V.S. Sangwan, S. Burman, S. Tejwani, S.P. Mahesh, R. Murthy. Indian J. Ophthalmol. 55 (2007) 251-260.

120. G.N. Rao, R.C. Khanna, S.M. Athota, V. Rajshekar, P.K. Rani. Indian J. Ophthalmol. 60 (2012) 396-400.

121. V.S. Sangwan, S. Basu, S. MacNeil, D. Balasubramanian. Br. J. Ophthalmol. 96 (2012) 931-934.

122. C. Ramachandran, S. Basu, V.S. Sangwan, D. Balasubramanian. Stem Cells Transl. Med. 3 (2014) 1160-1168.

123. F. Sefat, R. McKean, P. Deshpande, C. Ramachandran, C.J. Hill, V.S. Sangwan, A.J. Ryane, S. MacNeila. Procedia Eng. 59 (2013) 101-116. 